\title{
The Potential Use of Hypochlorous Acid and a Smart Prefabricated Sanitising Chamber to Reduce Occupation-Related COVID-19 Exposure
}

This article was published in the following Dove Press journal: Risk Management and Healthcare Policy

\author{
Kate Nguyen (D) \\ Dinh Bui ${ }^{2}$ \\ Mahak Hashemi ${ }^{1,3}$ \\ Dianna M Hocking ${ }^{4}$ \\ Priyan Mendis ${ }^{3}$ \\ Richard A Strugnell ${ }^{4}$ \\ Shyamali C Dharmage (D) ${ }^{2}$ \\ 'School of Engineering, RMIT University, \\ Melbourne, Victoria, Australia; ${ }^{2}$ Centre \\ of Epidemiology and Biostatistics, The \\ University of Melbourne, Melbourne, \\ Victoria, Australia; ${ }^{3}$ ARC Training Centre \\ on Advanced Manufacturing of \\ Prefabricated Housing, The University of \\ Melbourne, Melbourne, Victoria, \\ Australia; ${ }^{4}$ Department of Microbiology \\ and Immunology, Peter Doherty Institute \\ for Infection and Immunity, Melbourne, \\ Victoria, Australia
}

Correspondence: Shyamali C Dharmage Email s.dharmage@unimelb.edu.au

\begin{abstract}
This work is part of a project on the development of a smart prefabricated sanitising chamber (SPSC) to provide extra measures against the transmission of the severe acute respiratory syndrome coronavirus 2 (SARS-CoV-2). Stabilised hypochlorous acid $(\mathrm{HOCl})$ is an approved disinfectant against SARS-CoV-2 by the Environmental Protection Association US in its liquid form on non-porous surfaces. This review is extended to cover its viricidal/bactericidal efficacy in aerosolised or sprayed form which showed an effective dose of as low as $20 \mathrm{ppm}$ and the exposure duration of at least $60 \mathrm{~s}$. The aerosolised application was also recommended with particle size of less than $200 \mu \mathrm{m}$ to increase the contact with pathogens. The review also includes the safety and toxicity of $\mathrm{HOCl}$ with different concentrations. The review calls for more investigations into the effect of $\mathrm{HOCl}$ in mist and fog form on the respiratory system when transitioning through the proposed SPSC. Keywords: SARS-CoV-2, Sanitiser, occupational health, cross-contamination, healthcare management
\end{abstract}

\section{Introduction}

The novel coronavirus, named severe acute respiratory syndrome coronavirus 2 (SARS-CoV-2; COVID-19) has spread globally at an unprecedented rate with over 33 million infected cases and 1,012,341 deaths as of October 1, 2020. ${ }^{1}$ In Australia, a suppression strategy has been adopted since the start of the pandemic with the aim of maintaining a low transmission rate close to 1 or below to make sure the healthcare system does not exceed its capacity and proper medical treatment is performed on infected patients. ${ }^{2,3}$

To date, the extent of SARS-CoV-2 transmission and risk factors associated with infection are not fully understood; however, a scientific brief conducted by the World Health Organization (WHO) has stated that the main modes of transmission for SARS-CoV-2 include contact, droplet, airborne, fomite, fecal-oral and bloodborne with the potential for transmission between humans, mother-to-child and animal-to-human., ${ }^{4,5}$

While strategies with social distancing including different levels of lockdown, mask use and increased personal hygiene are effective in slowing the COVID-19 transmission rate, recent studies have provided evidence on transmission via aerosol ${ }^{6,7}$ or the fecal shedding of the virus, making toilets significant objects of transmission as they aerosolise some of the contaminants within faeces. ${ }^{8}$ This indicates the need for 
further measures to effectively suppress the virus. Individual respiratory protective devices including N95 respirators and medical masks have been used as critical tools to protect healthcare workers against COVID-19. ${ }^{9}$ However, studies have found increased levels of discomfort, including higher facial skin temperature and adverse skin reactions, and these could induce non-compliance. $^{10,11}$ As SARS-CoV-2 is known to remain viable for hours in aerosols and for days on surfaces, ${ }^{6}$ the importance of containment and prevention of cross-contamination in facilities with a high number of people frequently in contact with COVID-19 patients or people with high risk of carrying SARS-CoV-2 has been emphasised. Incorrect removal of personal protective equipment was known to contaminate $39 \%$ of healthcare workers with highly resistant micro-organisms. ${ }^{12}$ These containment measures are critical to public health safety especially where movement restrictions are relaxed, and new waves of infection are observed. ${ }^{13}$ These groups including doctors, nurses, aged-care workers, hospital staff or quarantine personnel. In the second wave of COVID-19 in Victoria, over 1,400 infected patients were healthcare workers and $70-80 \%$ of them were infected at work (as of August 27, 2020). ${ }^{14}$ This alarming infection rate not only puts the staff's health at risk but also hinders the response of the health service as trained professionals are isolated instead of giving care to patients. Particularly, more than 600 staff at Frankston Hospital, Victoria were in isolation following an outbreak at the facility. ${ }^{15}$

We have initiated a project on the development of a smart prefabricated sanitising chamber (SPSC) by way of aerosolised sanitation to disinfect COVID-19 exposed workers with minimal interruption of their operation and prevent cross-contamination. By minimising potential spread of SARS-CoV-2 at critical facilities such as COVID-19 treatment clinics and quarantine buildings for returned travellers, the use of the smart prefabricated sanitising chamber will help to prevent transmission into the broader community. Finding a suitable sanitiser is crucial to achieve a practical design for a SPSC (Figure 1).

\section{A Potential Disinfectant}

Wickramatillake and Kurukularatne ${ }^{16}$ analysed the viricidal efficacy of chloroxylenol, benzalkonium chloride and common bleaches against SARS-CoV-2, showing their effectiveness after 5 minutes of treatment. Hydrogen peroxide was also found to be used as a disinfectant against COVID-19 but this disinfectant has high reactivity and can act as a powerful oxidiser with metals. ${ }^{16}$ However, no commercially available data were shown on the efficacy of these disinfectants in aerosolised form or potential health impacts related to inhalation or contact with the skin. We have reviewed the evidence on the efficacy of hypochlorous acid $(\mathrm{HOCl})$ in different settings via different applications and compared bactericidal and viricidal activity of hypochlorous acid to other disinfectants such as sodium hypochlorite $(\mathrm{NaOCl})$, the most widely used disinfectant in the food industry, at the same free chlorine concentration.

$\mathrm{HOCl}$ is a weak acid which interacts with structural proteins such as the capsid or surface compounds, lipid envelope and DNA/RNA materials of viruses. ${ }^{17}$ The stability of $\mathrm{HOCl}$ is preserved by maintaining an optimal $\mathrm{pH}$ range of 3.5-5.5. HOCl can be generated by one of three methods: hydrolysis of chlorine gas, electrolysis of salt water, and acidification of hypochlorite. $\mathrm{HOCl}$ can be readily sourced commercially or generated inhouse. $\mathrm{HOCl}$ is listed in List N: Disinfectants for Use Against
A

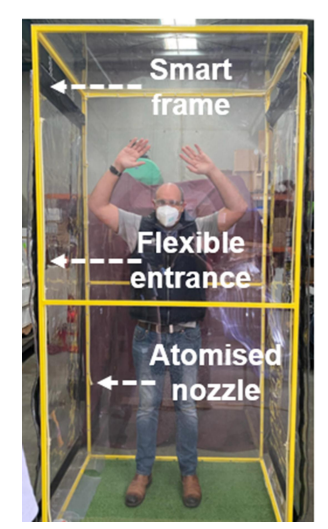

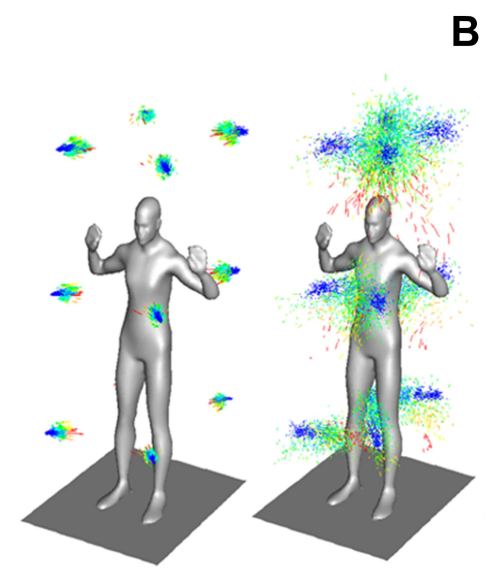

B

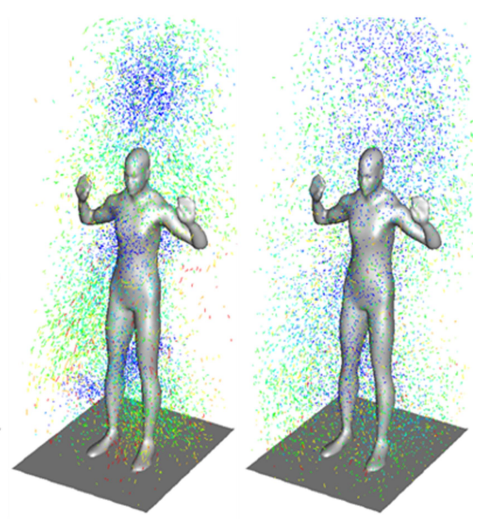

Figure I Prefabricated sanitising chamber: (A) prototype and (B) demonstration of aerosolised hypochlorous acid in the chamber. 
Table I Currently Listed Hypochlorous Acid Products Approved by United States Environmental Protection Agency (EPA) for Use Against SARS-CoV-2 as of October I, 2020

\begin{tabular}{|c|c|c|c|c|}
\hline $\begin{array}{l}\text { EPA Registration } \\
\text { Number }\end{array}$ & $\begin{array}{l}\text { To Kill SARS-CoV-2, Follow Disinfection } \\
\text { Directions For the Following Virus(es) }\end{array}$ & $\begin{array}{l}\text { Contact } \\
\text { Time } \\
\text { (Minutes) }\end{array}$ & Product Name & Supplier \\
\hline $93908-1$ & Norovirus & 10 & Envirolyte O \& G & Aqua Engineered Solution Inc. \\
\hline $92449-1$ & Rhinovirus & 10 & Annihilyte-I & Annihilare Medical Systems Inc. \\
\hline $87518-1$ & Norovirus & I & $\mathrm{Hsp} 2 \mathrm{O}$ & HSP USA LLC \\
\hline $92108-1$ & Norovirus & 10 & Excelyte Vet & PCT Ltd \\
\hline $85134-1$ & Norovirus & 10 & Envirocleanse A & Envirocleanse LLC \\
\hline $91582-1$ & Adenovirus; Rhinovirus & 10 & Danolyte & Danolyte Global Inc. \\
\hline $89896-2$ & Human coronavirus & 10 & Cleansmart & Simple Science Ltd \\
\hline
\end{tabular}

Note:Reproduced from United States Environmental Protection Agency [homepage on the Internet], US. 2020 August 20 List N: disinfectants for Use Against SARS-CoV-2 (COVID-19). Available from: https://www.epa.gov/pesticide-registration/list-n-disinfectants-use-against-sars-cov-2-covid-19. ${ }^{18}$

SARS-CoV-2 by the US Environmental Protection Agency (as shown in Table 1). ${ }^{18}$

Disinfectants and disinfection techniques should be safe for a long exposure time on personnel, equipment and surfaces used in the fight against coronavirus. Disinfection technologies for indoors are important to reduce transmission, especially in crowded settings. $\mathrm{HOCl}$ has been proposed as an effective disinfectant in various settings from food production, handling and preparation (farming and hospitality industry) to healthcare applications, including chronic wound care and eyelid infection management, as listed Table 2. ${ }^{19-21}$

\section{Efficacy}

While most disinfectants are tested or studied in their liquid form on non-porous surfaces, the viricidal/bactericidal efficacy of $\mathrm{HOCl}$ has also been studied when used in aerosolised/sprayed form and on porous surfaces. Hakimullah et al. ${ }^{17}$ present a comprehensive insight into the efficacy of $\mathrm{HOCl}$ in spray form to inactivate Escherichia coli and Salmonella with an effective concentration of $50-100$ ppm on rayon fabric. Another study ${ }^{22}$ found that $\mathrm{HOCl}$ exhibited higher bactericidal activity (4.4 $\left.\log _{10} \mathrm{CFU} / \mathrm{mL}\right)$ compared with $\mathrm{NaOCl}\left(1.3 \log _{10} \mathrm{CFU} / \mathrm{mL}\right)$ with the same concentration of $0.5 \mathrm{mg} / \mathrm{L}$. Results from spray experiments ${ }^{12}$ also showed that 20-minute exposure to sprayed $\mathrm{HOCl}$ of $0.01 \%$ was sufficient to reduce $99.5 \%$ of Staphylococcus epidermidis.

Another study by Wang et al. ${ }^{23}$ found the potential pharmaceutical application of stabilised $\mathrm{HOCl}$ in the control of soft tissue infection with a kill time of less than 2 minutes for 19 out of 20 pathogens. $\mathrm{HOCl}$ also had a shorter kill time than $\mathrm{NaOCl}$ and $\mathrm{H}_{2} \mathrm{O}_{2}$. Hao et al. ${ }^{24}$ recommended the use of $\mathrm{HOCl}$ as a mouth wash and hand sanitiser (at 100-200 ppm) and for surface application. They also recommended spray or fog application with an aerosol size of less than $20 \mu \mathrm{m}$, due to the fact that smaller particles in spray form may help $\mathrm{HOCl}$ molecules to be suspended in the air for a longer duration. This low settling velocity rate may increase the solution's chance of coming into contact with pathogens and inactivating them. When the aerosol was not sprayed directly onto an inoculated surface, a lower amount of solution had a chance to come into contact with the avian influenza virus. It required at least 10 minutes of contact to be effective. ${ }^{24}$

Another work ${ }^{25}$ also found the effective concentration of $\mathrm{HOCl}$ to be $200 \mathrm{ppm}$ in decontaminating inert surfaces carrying noroviruses and other enteric viruses in a 1-minute contact time. When diluted 10 -fold, $\mathrm{HOCl}$ solutions at 20 ppm were still effective in decontaminating environmental surfaces carrying viruses in a 10-minute contact time.

Disinfection in the form of an effective surface disinfectant, hand hygiene or air disinfection, is the major preventive measure in containing the novel coronavirus. High-risk exposed surface areas need to be cleaned frequently with a suitable disinfectant. The characteristic features of an ideal disinfectant are a low contact time with significant antiviral activity with it being safe for humans, the environment, surfaces and 
Table 2 Current Disinfecting Applications of Hypochlorous Acid

\begin{tabular}{|c|c|}
\hline Applications & Reference \\
\hline Hygiene solution on ocular skin & Stroman et al. ${ }^{20}$ \\
\hline Wound care agent and topical application & Wang et al., ${ }^{23}$ Rasmussen and Williams, ${ }^{29}$ Del Rosso and Bhatia ${ }^{30}$ \\
\hline Mouth wash and hand sanitizer & Hao et al. ${ }^{24}$ \\
\hline Biosecurity enhancement in poultry production & Hakim et al. ${ }^{17}$ \\
\hline $\begin{array}{l}\text { Decontamination agent against Shiga toxin-producing Escherichia coli on } \\
\text { fresh beef }\end{array}$ & Cap et al. ${ }^{21}$ \\
\hline Disinfecting dental unit water lines & Martin and Gallagher ${ }^{19}$ \\
\hline Cleaning and disinfecting $\mathrm{Gl}$ endoscopic procedure rooms & Overholt et al. ${ }^{26}$ \\
\hline Mist application for enclosed area & Galvin et al. $^{27}$ \\
\hline General surface disinfectant & $\begin{array}{l}\text { Hakim et al.., }{ }^{17} \text { Hao et al. }{ }^{24} \text { Rasmussen and Williams }{ }^{29} \text { Block and } \\
\text { Rowan }{ }^{31}\end{array}$ \\
\hline
\end{tabular}

Abbreviations: EPA, United States Environmental Protection Agency; FDA, US Food and Drug Administration; HOCl, hypochlorous acid; NaOCl, sodium hypochlorite; SARS-CoV-2, severe acute respiratory syndrome coronavirus 2; SPSC, smart prefabricated sanitising chamber; TGA, Australian Therapeutic Goods Administration; WHO, World Health Organization.

equipment. $\mathrm{HOCl}$ is approved by the Australian Therapeutic Goods Administration (TGA) as a disinfectant against COVID-19. The US Food and Drug Administration (FDA) has approved the use of hypochlorous acid for eye and dental spray application and as a no-rinse sanitiser for fruit and vegetables. With several studies on the sanitising power and effect of $\mathrm{HOCl}$, it has been shown to eliminate viruses, bacteria and spores at an acceptable reduction log with effective concentration of as low as 20 ppm and a kill time as low as 1 minute. Further research is required to determine the optimum exposure time with non-direct contact spray $\mathrm{HOCl}$ to ensure the viricidal efficacy in settings such as the proposed SPSC.

\section{Safety and Toxicity}

In terms of the safety and toxicity owing to the potential direct contact with ocular, skin and respiratory systems, stabilised $\mathrm{HOCl}$ has been found to be non-irritating (rabbit eye) and non-sensitising (guinea pig) in animal models. No ocular irritation was observed when $0.013 \%$ $\mathrm{HOCl}$ was sprayed into the eyes of Dutch pigmented rabbits every 8 hours for 72 hours. $^{23}$ Guinea pigs showed no evidence of dermal reaction when concentrations of $0.01 \%, 0.03 \%$, and $0.10 \% \mathrm{w} / \mathrm{v}$ stabilised $\mathrm{HOCl}$ were applied topically. A 28-day toxicity study with the same concentrations as the dermal study showed no evidence of systemic toxicity. ${ }^{23} \mathrm{HOCl}$ was also found to be an effective disinfectant that was 80-200 times more effective than standard disinfecting procedures while being non-toxic to humans. ${ }^{26}$ Van Doremalen et al. ${ }^{6}$ and Galvin et al. ${ }^{27}$ recommended $\mathrm{HOCl}$ use for offices with an emphasis on its use for dental clinics and the importance of fog or mist application ${ }^{28}$ of the disinfection given the aerosol property of the virus.

$\mathrm{HOCl}$ is safe and non-toxic for human and environmental use. It is also inexpensive with the flexibility of applying methods (spray mist, fog, liquid) which makes it an appropriate candidate as a choice of disinfectant for indoor settings on a regular basis. The presence of organic and reducing agents significantly reduces the effectiveness of hypochlorous acid ${ }^{21}$ and this is an area that needs to be studied further to provide robust conclusions. This review recommends further study in regard to the safety of $\mathrm{HOCl}$ with mist and fog application on respiratory system, skin and eyes, in the smart prefabricated sanitising chamber setting, acknowledging that the deployment of Brio HOCL ${ }^{\text {TM }}$ inactivates viruses, bacteria, endospores, and fungi and is safe for human tissues (including eye, lung, and skin). ${ }^{29}$ It should be noted that mist applications have already been approved for eyelid infection management, ${ }^{20}$ $\operatorname{skin}^{23}$ and $\operatorname{cosmetics}^{30}$ with repeated daily exposure for a set period of time. Other reviews by Block and Rowan ${ }^{31}$ and Scarano et al. ${ }^{32}$ found that hypochlorous acid had high predictability and low cost to disinfect against COVID-19 in oral-maxillofacial clinics by spraying small aerosol 
particles. This review calls for more investigations into the effect of $\mathrm{HOCl}$ in mist and fog form on the skin, eyes, and respiratory system when exposed in the proposed smart prefabricated sanitising chamber, especially in the presence of organic substances.

\section{Conclusion}

In this review on the use of stabilised hypochlorous acid (HOCl) as a potential disinfecting agent for the smart prefabricated sanitising chamber application, the current evidence on the viricidal efficacy, safety, and toxicity are presented. $\mathrm{HOCl}$ stabilised at the $\mathrm{pH}$ of $3.5-5.5$ is a weak acid which interacts with structural proteins or viral materials to inactivate micro-organisms. $\mathrm{HOCl}$ is currently a disinfectant for SARS-CoV-2 approved by the US Environmental Protection Association under different brands. $\mathrm{HOCl}$ with a concentration as low as $20 \mathrm{ppm}$ was found to be effective in disinfecting surfaces including porous rayon. Aerosolised or sprayed $\mathrm{HOCl}$ is effective in eliminating micro-strains such as Staphylococcus epidermidis after an exposure of $1 \mathrm{~min}$ to $20 \mathrm{mg} / \mathrm{L}$ (equivalent to $20 \mathrm{ppm}$ ). The safety and non-toxicity for humans and the environment, the low cost, and the flexibility of applying methods make $\mathrm{HOCl}$ an appropriate candidate of disinfectant for indoor settings such as offices, hospitals, and healthcare clinics. Further investigations into the effect of $\mathrm{HOCl}$ in mist and fog form on the skin, eyes, and respiratory system especially in special settings such as the proposed smart prefabricated sanitising chamber with presence of organic materials is recommended.

\section{Acknowledgments}

The authors would like to acknowledge the financial support from the Australian Research Council (Grant number: IC150100023 and DE290100217).

\section{Disclosure}

The authors report no conflicts of interest in this work.

\section{References}

1. John Hopkins University [homepage on the Internet], US. 2020 Available from: https://coronavirus.jhu.edu/. Accessed October 1, 2020.

2. Vardoulakis S, Sheel M, Lal A, Gray D. COVID-19 environmental transmission and preventive public health measures. Aust $N$ Z J Public Health. 2020;44(5):ePub. doi:10.1111/1753-6405.13033

3. Adekumle A, Meehan M, Rojas-Alvarez D, Trauer J, McBryde E. Delaying the COVID-19 epidemic in Australia: evaluating the effectiveness of international travel bans. Aust $N Z J$ Public Health. 2020;44(4):257-259. doi:10.1111/1753-6405.13016
4. World Health Organization [homepage on the Internet]. 2020 July 9. Transmission of SARS-CoV-2: implications for infection prevention precautions". Available from: https://www.who.int/. Accessed August 24, 2020.

5. Pascarella G, Strumia A, Piliego C, et al. COVID-19 diagnosis and management: a comprehensive review. J Int Med. 2020;288(2):192206. doi:10.1111/joim.13091

6. van Doremalen N, Bushmaker T, Morris DH, et al. Aerosol and surface stability of SARS-CoV-2 as compared with SARS-CoV-1. N Engl J Med. 2020;382:1564-1567. doi:10.1056/NEJMc2004973

7. Therapeutic goods Administration [homepage on the Internet]. 2020 August 25. Disinfectants for use against COVID-19 in the ARTG for legal supply in Australia. Available from: https://www.tga.gov.au/ disinfectants-use-against-covid-19-artg-legal-supply-australia.

Accessed August 24, 2020

8. Chen Y, Chen L, Deng Q, et al. The presence of SARS-CoV-2 RNA in the feces of COVID-19 patients. J Med Virol. 2020;92(7):833-840. doi: $10.1002 / \mathrm{jmv} .25825$

9. Cook TM. Personal protective equipment during the coronavirus disease (COVID) 2019 pandemic - a narrative review. Anaesth. 2020;75(7):920-927. doi:10.1111/anae.15071

10. Hua W, Zuo Y, Wan R, et al. Short-term skin reactions following use of N95 respirators and medical masks. Contact Dermatitis. 2020;83 (2):115-121. doi:10.1111/cod.13601

11. Scarano A, Inchingolo F, Lorusso F. Facial skin temperature and discomfort when wearing protective face masks: thermal infrared imaging evaluation and hands moving the mask. Int J Environ Res Public Health. 2020;17(3):4624. doi:10.3390/ijerph17134624

12. Okamoto K, Rhee Y, Schoeny M, et al. Impact of doffing errors on healthcare worker self-contamination when caring for patients on contact precautions. Infect Control Hosp Epidemiol. 2019;40 (5):559-565. doi:10.1017/ice.2019.33

13. Department of Health and Human Services, Victoria State Government [homepage on the Internet]. 2020 August 24. Available from: https://www.dhhs.vic.gov.au/. Accessed August 24, 2020.

14. Lai J, Cheong K. Superposition of COVID-19 waves, anticipating a sustained wave, and lessons for the future. BioEssays. 2020:2000178.

15. ABC News [homepage on the Internet]. 2020 August 26 Available from: https://www.abc.net.au/news/2020-08-26/coronavirus-out break-at-frankston-hospital-in-melbourne-grows/12597734. Accessed October 1, 2020.

16. Wickramatillake A, Kurukularatne C. SARS-CoV-2 human disinfection chambers: a critical analysis. Occup Med. 2020;70(5):330-334. doi:10.1093/occmed/kqaa078

17. Hakim H, Alam MS, Sangsriratanakul N, et al. Inactivation of bacteria on surfaces by sprayed slightly acidic hypochlorous acid water: in vitro experiments. Vet Med Sci. 2016;78(7):1123-1128. doi:10.1292/jvms.160075

18. United States Environmental Protection Agency [homepage on the Internet], US. 2020 August 20 List N: disinfectants for Use Against SARS-CoV-2 (COVID-19) Available from: https:/www.epa.gov/pes ticide-registration/list-n-disinfectants-use-against-sars-cov-2-covid19. Accessed August 24, 2020.

19. Martin MV, Gallagher MA. An investigation of the efficacy of superoxidised (Optident/Sterilox) water for the disinfection of dental unit water lines. BDJ Open. 2005;198(6):353-354. doi:10.1038/sj.bdj.4812174

20. Stroman DW, Mintun K, Epstein AB, et al. Reduction in bacterial load using hypochlorous acid hygiene solution on ocular skin. Clin Ophthalmol. 2017;11:707-714. doi:10.2147/OPTH.S132851

21. Cap M, Vaudagna S, Mozgovoj M, et al. Inactivation of Shiga toxinproducing Escherichia coli in fresh beef by electrolytically-generated hypochlorous acid, peroxyacetic acid, lactic acid and caprylic acid. Meat Sci. 2019;157:107886. doi:10.1016/j.meatsci.2019.107886

22. Naka A, Yakubo M, Nakamura K, Kurahashi M. Effectiveness of slightly acidic electrolyzed water on bacteria reduction: in vitro and spray evaluation. Peer J. 2020;8:e8593. doi:10.7717/peerj.8593 
23. Wang L, Bassiri M, Najafi K, et al. Hypochlorous acid as a potential wound care agent: part I. Stabilized hypochlorous acid: a component of the inorganic armamentarium of innate immunity. J Burns Wounds. 2007;6:e5.

24. Hao XX, Li BM, Zhang Q, et al. Disinfection effectiveness of slightly acidic electrolysed water in swine barns. J Appl Microbiol. 2013;115 (3):703-710. doi:10.1111/jam.12274

25. Block MS, Rowan BG. Hypochlorous acid: a review. J Oral Maxillofac Surg Med Pathol. 2020;78(9):1461-1466.

26. Overholt B, Reynolds K, Wheeler D, Safer A. More effective method for cleaning and disinfecting GI endoscopic procedure rooms. Open Forum Infect Dis. 2018;5(1):s346. doi:10.1093/ofid/ofy210.984

27. Galvin S, Boyle M, Russell R, et al. Evaluation of vaporised hydrogen peroxide, Citrox and $\mathrm{pH}$ neutral Ecasol for decontamination of an enclosed area: a pilot study. J Hosp Infect. 2012;80:67-70. doi:10.1016/j.jhin.2011.10.013
28. Sotiriou M, Ferguson SF, Davey M, et al. Measurement of particle concentrations in a dental office. Environ Monit Assess. 2008;137 (1):351-361. doi:10.1007/s10661-007-9770-7

29. Rasmussen ED, Williams JF. Stabilized hypochlorous acid disinfection for highly vulnerable populations: brio HOCL ${ }^{\mathrm{TM}}$ wound disinfection and area decontamination. Proc IEEE Glob Humanit Technol Conf. 2017.

30. Del Rosso JQ, Bhatia N. Status report on topical hypochlorous acid: clinical relevance of specific formulations, potential modes of action, and study outcomes. J Clin Aesthet Dermatol. 2018;11(11):36-39.

31. Block M, Rowan B. Hypochlorous acid: a review. J Oral Maxillofac Surg. 2020;78(9):1461-1466.

32. Scarano A, Inchingolo F, Lorusso F. Environmental disinfection of a dental clinic during the Covid-19 pandemic: a narrative insight. Biomed Res Int. 2020;8896812.
Risk Management and Healthcare Policy

\section{Publish your work in this journal}

Risk Management and Healthcare Policy is an international, peerreviewed, open access journal focusing on all aspects of public health, policy, and preventative measures to promote good health and improve morbidity and mortality in the population. The journal welcomes submitted papers covering original research, basic science, clinical \& epidemiological studies, reviews and evaluations,

\section{Dovepress}

guidelines, expert opinion and commentary, case reports and extended reports. The manuscript management system is completely online and includes a very quick and fair peer-review system, which is all easy to use. Visit http://www.dovepress.com/testimonials.php to read real quotes from published authors. 